\title{
Características de Altas Habilidades/Superdotação em Aluno Precoce: um Estudo de Caso ${ }^{1}$ High Abilities/Giftedness Characteristics in one Precocious Student: A CASE STUDY
}

\author{
Bárbara Amaral MARTINS ${ }^{2}$ \\ Miguel Claudio Moriel $\mathrm{CHACON}^{3}$
}

\begin{abstract}
RESUMO: a precocidade é um fenômeno ainda pouco estudado nacionalmente. Desse modo, considera-se relevante o empreendimento de investigaçôes acerca de estudantes que demonstram habilidades precocemente desenvolvidas a fim de contribuir para o crescimento do conhecimento científico sobre a temática. Frente a essa problemática, o objetivo deste estudo foi verificar se um aluno precoce apresentava características de altas habilidades/superdotação de acordo com literatura, em especial as que se relacionam à criatividade e à aprendizagem. Os dados foram coletados por meio de observaçóes desse aluno em relação à leitura e escrita em situaçôes escolares. Também foram realizadas entrevistas com seus pais. As observaçôes foram registradas em diários de campo, ao passo que a entrevista foi gravada e integralmente transcrita. A análise ocorreu qualitativamente. Os resultados demonstraram a presença de características de altas habilidades/superdotação no comportamento do aluno e apontaram para a necessidade de atenção educacional que considere e respeite suas peculiaridades e estimule o desenvolvimento de suas potencialidades, porém, sem perder de vista suas necessidades próprias da infância.
\end{abstract}

PALAVRAS-CHAVE: Educação Especial. Precocidade. Altas habilidades. Superdotação.

\begin{abstract}
Precocity is a phenomenon still little studied nationally. Thus, investigations about students who demonstrate prematurely developed skills are considered relevant in order to contribute to the growth of scientific knowledge on the subject. In this context, the objective this study was to verify whether one precocious student presented high abilities/giftedness features according to the literature, in particular those related to creativity and learning. Data were collected through observations of this student in reading and writing school situations. Interviews were conducted with his parents. Observations were recorded in field diaries, while the interviews were recorded and transcribed in full. The analysis was qualitative. The results showed the presence of high ability/giftedness characteristics in student's behavior and pointed to the need for educational care to consider and respect his peculiarities and encourage the development of his potential, but without losing sight of his needs characteristically of childhood.
\end{abstract}

KEYWORDS: Special Education. Precocity. High Abilities. Giftedness.

\section{INTRODUÇÁo}

Na perspectiva da educação inclusiva, a escola regular deve promover as condiçóes necessárias para a aprendizagem e o desenvolvimento de todos os seus alunos, inclusive aqueles que apresentam deficiências, transtornos globais do desenvolvimento e altas habilidades/ superdotação (AH/SD). Todavia, os alunos que compóem este último grupo, embora sempre presentes no ensino regular, não têm recebido a devida atenção educacional, uma vez que é comum passarem despercebidos pelos bancos das instituições de ensino.

${ }^{1}$ Apoio financeiro: Coordenação de Aperfeiçoamento de Pessoal de Nível Superior (CAPES)

http://dx.doi.org/10.1590/S1413-65382216000200004

${ }^{2}$ Professora Assistente da Universidade Federal do Mato Grosso do Sul, Campus do Pantanal. Mato Grosso do Sul, MS, Brasil. barbara.martins@ufms.br

${ }^{3}$ Docente do Departamento de Educação Especial e do Programa de Pós-Graduação em Educação da Unesp, Campus de Marília. Marília, SP, Brasil. miguelchacon@marilia.unesp.br 
Segundo Fortes e Freitas (2007), a negligência com esse público está relacionada à falta de informação, pois sem conhecimentos sobre o fenômeno $\mathrm{AH} / \mathrm{SD}$, o professor não se dá conta da presença desses alunos e, uma vez não identificados, são privados do ensino que necessitam para desenvolver ao máximo o potencial que possuem.

A superação das dificuldades que impedem a efetivação do ensino adequado aos alunos com AH/SD torna-se urgente, na medida em que, quando não são reconhecidos e estimulados, correm o risco de se adaptarem ao contexto rotineiro da sala de aula, deixando de desenvolver suas habilidades e, até mesmo, tornando-se desinteressados e frustrados (FREEMAN; GUENTHER, 2000). Mas, se as pesquisas sobre AH/SD realizadas no Brasil não atingem um número expressivo (FREITAS, 2014), há um subgrupo que tem recebido atenção ainda menor em cenário nacional: o aluno precoce.

O aluno precoce é aquele que se destaca perante crianças da mesma idade, em razão habilidades que apresenta, porém, estas tanto podem ser a expressão de um potencial superior, o qual pode estar sinalizando o que chamaremos de superdotação ${ }^{4}$, quanto podem ter suas origens na simples prematuridade do desenvolvimento de aspectos cognitivos, que se normalizarão com o decorrer do tempo. Independentemente de qual for o motivo que faça com que essa criança destoe das demais, sua diversidade demanda educação especial, mas apesar da importância da atenção à precocidade, em um levantamento junto ao banco de teses e dissertaçóes da Coordenação de Aperfeiçoamento de Pessoal de Nível Superior (CAPES) e à Biblioteca Digital Brasileira de Teses e Dissertaçôes (BDTD) foram encontrados somente três ${ }^{5}$ trabalhos destinados ao estudo dessa temática: Câmara (1999) procurou verificar a relação entre autoalfabetização precoce e superdotação, além das variáveis ambientais favorecedoras; Forno (2011) objetivou investigar se a criança precoce é reconhecida na Educação Infantil e qual é o lugar que ocupa, no processo de escolarização, enquanto Marques (2013) buscou reconhecer os indicadores característicos da criança precoce, a partir das percepçóes de pais e professores.

Desse modo, nota-se que ainda pouco se sabe sobre quem são essas crianças e quais as características que apresentam. Nesse sentido, temos por objetivo verificar a presença de características de altas habilidades/superdotação presentes na literatura, no comportamento de um aluno precoce, em especial as que se relacionam à criatividade e à aprendizagem.

Vale esclarecer que essa caracterização não objetiva traçar um perfil de aluno com AH/SD, uma vez que não há homogeneidade entre tais educandos. Conforme Alencar e Fleith (2001), cada um evidenciará uma combinação própria de inteligência, personalidade e desempenho, de modo a demonstrar características diversificadas.

\footnotetext{
${ }^{4}$ Cupertino (2008), ao diferenciar superdotação de altas habilidades coloca aquele como representante do desempenho superior que um indivíduo apresenta, de modo a ultrapassar a média de seus pares em uma ou mais das seguintes áreas: acadêmica, motora, artística, liderança e criatividade, enquanto o termo altas habilidades é mais amplo e engloba as gradações de um mesmo fenômeno: habilidade superior, superdotação, precocidade, prodígio e genialidade.

${ }^{5}$ No ano de 2013, também foi concluída nossa dissertação de mestrado, intitulada: Alunos precoces com indicadores de altas habilidades/superdotação no Ensino Fundamental I: identificação e situaçōes (des) favorecedoras em sala de aula.
} 
Assim, enquanto um deles pode apresentar uma competência elevada em uma grande diversidade de áreas aliada a uma liderança superior, outro pode mostrar-se extraordinariamente competente em apenas uma área, sendo, porém, imaturo emocionalmente; ainda outro poderá ser fisicamente menos desenvolvido, apresentando, contudo, uma habilidade significativamente superior (ALENCAR; FLEITH, 2001, p.67).

Dessa forma, é imprescindível ter clareza sobre a existência de indicadores de $\mathrm{AH} /$ $\mathrm{SD}$, porém, sem cair em idealizaçóes e estereotipias, pois se trata de crianças reais e únicas em sua constituiçáo, as quais não manifestam os indicadores da mesma maneira, tampouco com a mesma intensidade.

\section{Método}

Este estudo teve como participante um aluno precoce em leitura e escrita, matriculado no primeiro ano do Ensino Fundamental, que frequentava o Programa de Atençáo a alunos Precoces com indicadores de Altas Habilidades/Superdotação (PAPAHS), da Faculdade de Filosofia e Ciências da UNESP, campus de Marília, e também seus pais ${ }^{6}$.

O aluno participante, que será ficticiamente nomeado como Vinny, demonstrou seu interesse pelas letras táo logo quanto começou a falar, de maneira que com um ano e seis meses já era capaz de identificar a todas. Com três anos de idade passou a decodificar algumas palavras e aos quatro, sem nunca ter recebido qualquer tipo de instruçáo formal, já era capaz de ler e produzir textos intencionalmente.

Para verificarmos se Vinny apresentava características de AH/SD, inicialmente realizamos um levantamento bibliográfico envolvendo livros, artigos, teses e dissertaçóes que resultou em uma lista com 109 características apontadas na literatura científica e que, a exemplo da publicação do MEC (BRASIL, 2002), foram divididas em: características gerais, de pensamento criativo e de aprendizagem. Tivemos a referida lista como um parâmetro para a coleta e análise dos dados.

A coleta de dados se deu por meio de observaçáo do aluno em sala de aula e demais espaços escolares, uma vez por semana, em dias alternados, durante nove semanas. Nosso olhar foi guiado por um roteiro de observação que nos remetia aos comportamentos e desempenhos do participante, bem como ao contexto em que estes eram apresentados. Os dados eram registrados em diário de campo.

A fim de náo interferir na dinâmica de sala de aula, optamos por empregar a observação não participante, técnica em que o pesquisador atua apenas como um espectador, que, pautado nos objetivos da pesquisa, vê e registra o maior número de fatos que interessam ao seu estudo (RICHARDSON, 1999). Contudo, nem sempre era possível somente observar e, assim, acabávamos por interagir com o ambiente, por exigência das situaçóes. Isso ocorria em virtude da aproximação dos alunos, os quais queriam saber o que estava sendo escrito no diário de campo, perguntavam sobre as atividades que deveriam realizar, solicitavam ajuda para amarrar

\footnotetext{
${ }^{6}$ Seguindo as recomendaçōes da Resolução 196/96 do Conselho Nacional de Saúde, o projeto de pesquisa foi submetido ao Comitê de Ética em Pesquisa da Faculdade de Filosofia e Ciências da UNESP - Campus de Marília/SP - e aprovado sob o parecer no $0406 / 2011$.
} 
os calçados, reclamavam de algum colega ou procuravam estabelecer um diálogo. Assim como as professoras, que nos questionavam sobre a pesquisa, faziam relatos sobre os alunos observados, pediam opinióes e auxílio para "cuidar" dos alunos, quando precisavam se ausentar da sala. Dessa forma, concordamos com Tureta e Alcadipani (2011), quanto à existência de gradaçóes entre a observação participante e nâo participante, as quais rejeitam a oposição radical entre elas, pois, embora não intencionalmente, passávamos a participar de maneira ativa no grupo. Essa participação tornava-se favorável na medida em que contribuía para o estabelecimento de uma relação mais próxima entre os envolvidos, uma vez que, segundo Richardson (1999), é imprescindível que o observador (participante ou não participante) mantenha uma relação de confiança com os observados.

Também realizamos uma entrevista semiestruturada com os pais do aluno, que teve duração de 1 h 18 min 18 s e versava sobre a precocidade da criança desde o seu nascimento, e eventos da vida cotidiana. A entrevista foi gravada e integralmente transcrita.

Os dados foram analisados qualitativamente, a partir de leituras dos registros em diários de campo e das transcriçóes das entrevistas. Durante as leituras, e com base na lista de características que constam na literatura, identificávamos os trechos que indicavam a presença das características de AH/SD e estes eram recortados e colados em quadros que ilustravam a manifestação das mesmas. A fim de garantirmos a fidedignidade de nossa análise, contamos com a participação de cinco juízes (J1, J2, J3, J4 e J5) que receberam uma lista com as características identificadas, seguidas dos trechos dos diários de campo ou das entrevistas transcritas, que, a nosso ver, as evidenciavam. Solicitamos para que assinalassem se concordavam ou não com a presença da característica em destaque, no trecho apresentado. Nos casos de discordância, o juiz deveria apontar o motivo. Por fim, aplicamos o índice de concordância $(I C=$ (número de concordâncias/(concordâncias +discordâncias)) x 100), considerando aceitável o IC igual ou superior a $70 \%$.

Foram constatadas 61 características de altas habilidades/superdotação no participante do estudo, sendo 28 delas classificadas como Características Gerais de AH/SD, 10 como de Pensamento Criativo e 23 enquanto Características de Aprendizagem. Neste artigo, serão apresentadas e discutidas as características de Pensamento Criativo e Aprendizagem.

\section{Resultados E Discussóes}

As Características de Pensamento Criativo são de extrema relevância na medida em que a criatividade é um dos componentes da superdotação, ao lado da habilidade acima da média e do comprometimento com a tarefa (RENZULLI; REIS, 1985). Nessa perspectiva, as Características de Aprendizagem se relacionam à habilidade acima da média, que por sua vez, faz com que determinados alunos se destaquem facilmente no grupo de estudantes.

Tanto as características de aprendizagem quanto as de pensamento criativo são constantes no ambiente escolar, entretanto, o desconhecimento a respeito da precocidade e das $\mathrm{AH} /$ SD faz com que esses indicadores não recebam a merecida atenção por parte dos educadores. A seguir, apresentam-se as características verificadas no comportamento do participante da pesquisa. 


\subsection{Características de Pensamento Criativo}

No Quadro 1, são apresentadas as Características de Pensamento Criativo demonstrada pelo aluno participante.

\begin{tabular}{|l|l|}
\hline \multicolumn{2}{|c|}{ Características de Pensamento Criativo } \\
\hline Imaginação & Senso de humor avançado para sua idade \\
Criatividade & Preferência por atividades novas e criadoras a tarefas \\
Gosto por enfrentar desafios e correr riscos & rotineiras e repetitivas \\
Construir histórias vívidas e dramáticas & Coragem em tentar descobrir se suas ideias têm valor, \\
Flexibilidade & sem medo das críticas \\
Apresentar ideias inesperadas ou originais e & Menor inibição intelectual para discordar, expor \\
extravagantes & ideias e opinióes \\
\hline
\end{tabular}

Quadro 1 - Características de Pensamento Criativo apresentadas pelo participante do estudo. Fonte: Elaboração própria.

A imaginação era uma característica presente em Vinny, a qual tornava-se visível quando o aluno atribuía novos significados ao material escolar, fazendo com que o lápis se transformasse em espada, injeção ou flecha para o arco imaginário, o apontador virava copo de suco e fingia estar fotografando ou tocando violão. Criava histórias com facilidade e atribuía significado para aquilo que ouvia, por meio de imagens mentais.

Quando a professora disse a uma aluna que ela havia feito letrinhas voando, Vinny riu e começou a desenhar com seus dedos, letras no ar (Registros do diário de campo).

No que se refere à criatividade, demonstrou tal característica ao inserir elementos pouco usuais em dois de seus desenhos. Ao desenhar um cachorro mamando, permeou a ilustração com pegadas grandes e pequenas que representavam os passos da mãe e de seu filhote. Quando teve que desenhar filhotes de raposa, acabou por incluir, além desses, outras raposas, as quais eram pai, mãe e avô dos filhotes. Sua criatividade também foi evidenciada, quando criou um nome bastante original para um animal por ele imaginado: borboletassauro.

Manzano (2009) elucida que, embora exista algum grau de correlação, criatividade e inteligência geral não são significativamente paralelas, de maneira que o autor divide os superdotados em três grupos: superdotados com alta inteligência e baixa criatividade; superdotados com alta inteligência e alta criatividade; superdotados com baixa inteligência (QI por volta de 120) e alta criatividade.

O gosto por enfrentar desafios e correr riscos foi observado ao manifestar seu desejo por atividades desafiadoras.

- Abram a apostila na página 144 - diz a professora.

Ao ver a atividade, Vinny se queixa:

- Ah, essa lição é muito fácil! (Registros do diário de campo).

Para Benito (2000), além de não levar o aluno a aprender e a progredir, a falta de atividades compatíveis com seu nível de desenvolvimento pode fazê-lo desmotivar-se e desinteressar-se pela aprendizagem escolar, problema que se resolve quando o professor considera 
os conhecimentos prévios dos educandos, tomando-os como ponto de partida da intervenção pedagógica, para não insistir naquilo que já está consolidado, tampouco esperar menos do que as capacidades do aluno lhe permitem.

A característica construir histórias vívidas e dramáticas foi exibida quando houve a possibilidade de criar um teatro sobre dinossauros, situação na qual a professora precisou pedir para que finalizasse sua história, pois ultrapassara o tempo disponível sem dar sinais de que estava próximo de concluí-la, porém, ressalta-se que esta característica foi apresentada uma única vez, devido ter sido esta a única oportunidade para tal. Segundo Marques (2013), é por meio da capacidade elevada de contar histórias variadas, coerentes e ricas em detalhes que as crianças precoces manifestam o domínio da linguagem.

Sua flexibilidade pôde ser percebida quando, de forma muito tranquila, abriu mão de jogar com determinado personagem, a fim de evitar um desentendimento com seu colega, numa situação que tende a ser conflituosa em crianças nessa faixa de idade:

Escolheram mudar o personagem do jogo. Vinny disse que seria a Fifi e João disse exacerbadamente, que ele é quem queria ser essa personagem, entáo Vinny concordou, aceitando ser a Croquete (Registros do diário de campo).

Vinny apresentou uma ideia original e extravagante, quando, frente à instrução de desenhar um coelho grande, disse que desenharia um coelho passeando em uma floresta. Nessa mesma ocasiāo, expressou sua coragem em descobrir o valor de suas ideias quando foi perguntar à pesquisadora o que achava do desenho que ele estava produzindo, após a professora de Arte ter-lhe sugerido que o melhorasse, visto que o coelho desenhado não era grande e faltavam detalhes para indicar o local onde estava, o período do dia etc.

Demonstrou ter um senso de humor avançado para sua idade ao fazer os outros alunos rirem, trocando o sobrenome dos colegas cujo caderno a professora estava entregando. Além de uma imaginação fértil, revelou senso de humor quando ria e desenhava letras no ar, depois de ouvir a professora dizer a uma aluna que ela havia feito letrinhas voando. Tal característica também foi verificada por Becker (1997), em seu estudo com crianças precoces.

Sua preferência por atividades novas e criadoras a tarefas rotineiras e repetitivas evidenciou-se em situaçóes nas quais o aluno se queixava das atividades já conhecidas ou dispersava sua atenção quando tinha que ouvir todos os colegas darem suas respostas, as quais muitas vezes se repetiam. Em contrapartida, superou as expectativas e enriqueceu a aula, levando livro e brinquedo pertinente ao tema, quando a aula girou em torno de uma pesquisa sobre dinossauros realizada pelos alunos, a qual se constituía em uma atividade nova e criadora.

Na vez do próximo colega, a professora chamou a atenção de Vinny e João, que não estavam prestando atenção. Vinny ficou quieto e leu sua apostila por algum tempo, depois começou a riscar ou desenhar na mesa. Durante a apresentação do último colega, Vinny, João e Thaís começaram a brincar com seus dinossauros e foram repreendidos por isso (Registros do diário de campo).

O exemplo nos mostra que Vinny não era o único a se entediar com atividades repetitivas, visto que o mesmo ocorria com seus amigos, João e Thaís. Contudo, diante de uma 
atividade nova e criadora, no caso a pesquisa sobre dinossauros, não houve outra criança a apresentar tamanho envolvimento quanto o seu.

Renzulli (2000) considera que a repetição é desnecessária para aqueles que dominam os conteúdos de maneira mais rápida e recomenda a compactação do currículo, para esses alunos. Segundo Panzeri (2006), a compactação do currículo é necessária ao enriquecimento curricular e possui três objetivos: criar um ambiente de aprendizagem mais adequado às características do aluno; garantir o domínio do currículo básico para a etapa/ano escolar; e "ganhar tempo" para as atividades de que visam ao desenvolvimento das capacidades e interesses do estudante.

Para compactar o currículo, o professor precisa avaliar os conhecimentos de todos os estudantes, antes de introduzir um novo tema, de modo a reconhecer os que dominam previamente os conteúdos a serem trabalhados e, a partir de então, oferecer-lhes atividades substitutivas que podem ser realizadas individualmente ou em pequenos grupos (RENZULLI, 2000). Essa medida impede que o aluno desperdice seu tempo com aquilo que já conhece e permite que o utilize para se aprofundar em determinados assuntos ou desenvolver estudos e projetos de seu interesse.

Vinny apresentou a característica menor inibição intelectual para discordar, expor ideias e opinióes ao expressar seu descontentamento com algumas atividades propostas e ao discordar de colegas e professores, quando acreditava que eles estavam errados, mesmo que equivocadamente.

A professora foi fazendo o exercício na lousa juntamente com seus alunos e, quando colocou que havia quatro figuras em uma página e três na outra, representando com $4+3=7$, Vinny disse, em tom elevado:

- Não, tem cinco, você errou. (Registros do diário de campo).

A professora pediu para que achassem a palavra $\mathrm{BICHO}$ no poema e contassem quantas vezes ela aparecia. Após um tempo, a professora disse que a palavra aparecia três vezes, mas Vinny discordava e dizia que só aparecia duas vezes. (Registros do diário de campo).

Segundo Renzulli (2004), a criatividade é um dos fatores indispensáveis para que o indivíduo atinja altos níveis de produtividade com qualidade excepcional. Entretanto, não se trata de algo que se tem ou não: para Nakano e Weschsler (2007), a criatividade está presente, em algum grau, em todas as pessoas, porém guardados os diferentes níveis de intensidade. Além disso, a criatividade - como as demais características de pensamento criativo - é educacionalmente influenciável (ALENCAR; FLEITH, 2001). Em decorrência, as situaçóes do ambiente tanto podem incentivar quanto impedir seu desenvolvimento.

Nesse sentido, Alencar (2001) esclarece que o potencial criador está intrinsecamente relacionado ao ensino proporcionado, visto que os métodos de ensino que favorecem a expressão criadora são aqueles em que o aluno é levado a pensar por si só, testar suas ideias, manifestar a curiosidade e pôr em prática diversas habilidades intelectuais. Por outro lado, enfatizando a memorização e a transmissáo de conhecimentos do professor para o aluno, do qual se espera que os reproduza, a criatividade tende a ser inibida. 


\subsection{Características de Aprendizagem}

As características de aprendizagem são entendidas como aquelas que, embora possam ser visualizadas em outros contextos do cotidiano, se apresentam com maior frequência no ambiente escolar.

O Quadro 2 apresenta as Características de Aprendizagem do participante da pesquisa.

\begin{tabular}{|c|c|}
\hline \multicolumn{2}{|c|}{ Características de Aprendizagem } \\
\hline $\begin{array}{l}\text { Amplitude de foco (estar atento a várias coisas ao } \\
\text { mesmo tempo) } \\
\text { Habilidade em áreas específicas } \\
\text { Agilidade mental } \\
\text { Capacidade para pronta resposta } \\
\text { Precocidade, gosto e nível elevado de leitura } \\
\text { Prazer pela atividade intelectual } \\
\text { Rapidez e facilidade na aprendizagem e na utilização } \\
\text { dos conhecimentos } \\
\text { Boa memória } \\
\text { Capacidade de manter a concentração e a atenção por } \\
\text { longos períodos em atividades de seu interesse } \\
\text { Tendência a gostar do ambiente escolar } \\
\text { Estabelece relaçôes entre causa e efeito } \\
\text { Pensamento crítico }\end{array}$ & $\begin{array}{l}\text { Distração, tédio e desmotivação quando a tarefa não } \\
\text { lhe é interessante } \\
\text { Amplo vocabulário } \\
\text { Procura ser superior em quase tudo que faz } \\
\text { Faz relatos ricos em detalhes } \\
\text { Explorar temas em profundidade } \\
\text { Estabelece relações entre informações adquiridas ante- } \\
\text { riormente e novos conhecimentos } \\
\text { Capacidade para fazer generalizaçóes } \\
\text { Encontra satisfação pensando e discutindo sobre o que } \\
\text { leu } \\
\text { Rapidez na identificação de inconsistências } \\
\text { Rapidez em estabelecer relaçóes e compreender signi- } \\
\text { ficados } \\
\text { Atitude de questionamento e busca por informações }\end{array}$ \\
\hline
\end{tabular}

Quadro 2 - Características de Aprendizagem apresentadas pelo participante do estudo.

Fonte: Elaboração própria.

A amplitude de foco do aluno foi evidenciada, quando, apesar de envolvido na realização de suas atividades, respondia a perguntas que outros alunos dirigiam à professora.

Quanto à habilidade em áreas especificas, Vinny se sobressaía em língua portuguesa por meio de sua escrita e leitura precoces, domínio da ortografia e interpretaçáo de textos. Exibia amplo vocabulário na disciplina de inglês e, ao pesquisar, superava seus colegas no volume de informaçóes que encontrava.

Sua agilidade mental era exibida durante as indagaçóes da professora à classe ou a outros colegas, situaçóes em que o aluno respondia de maneira tấo rápida, que a professora lhe solicitava para que desse a chance de outros responderem. $\mathrm{O}$ aluno também era ágil em responder às perguntas que os colegas faziam à própria professora. De acordo com Maldaner (1996), é comum que, em sala de aula, a criança precoce, a qual a autora denomina criança superdotada, manifeste agitaçấo e incomode os professores com suas perguntas ou ao não dar espaço para outros colegas responderem aos questionamentos.

Entendemos que a capacidade para pronta resposta associa-se à agilidade mental, consequentemente, algumas vezes, ambas se fazem presentes na mesma situação. Vinny apresentou a capacidade para pronta resposta respondendo aos questionamentos feitos pela professora aos alunos ou vice-versa e, justificando seu desinteresse pelo estudo dos animais com o argumento de que a natureza a qual gostava era a real e não uma ilustração. 
Vinny demonstrou precocidade, gosto e nivel elevado de leitura, durante as observaçóes, quando lia oralmente textos e exercícios, tanto por solicitação da professora quanto por iniciativa própria, quando auxiliava seus colegas na leitura e quando escolhia essa atividade para preencher seu tempo disponível.

A professora pediu para que Vinny fizesse a leitura de um texto informativo com mais ou menos vinte linhas. Leu fluentemente e respeitando a pontuaçáo. (Registros do diário de campo).

O prazer pela atividade intelectual pôde ser percebido por meio de seu entusiasmo em falar sobre o que compreendeu dos textos lidos, responder a questóes orais, expor assuntos pesquisados e aprender inglês. Seu prazer pela leitura pôde ser percebido tanto quando antecipava as leituras da professora como quando pedia para ler para classe.

A característica rapidez e facilidade na aprendizagem e utilização dos conhecimentos foi percebida ao queixar-se da facilidade de algumas atividades, ao ser o primeiro a responder perguntas feitas à classe ou até mesmo a outros colegas e ao traduzir palavras presentes nas aulas de inglês, sem que isso fosse solicitado.

Vinny demonstrou ter boa memória nas situaçóes em que foi o único a se lembrar de determinadas informações fornecidas anteriormente.

$\mathrm{O}$ aluno mantinha-se concentrado por longos periodos de tempo somente em atividades de leitura ou naquelas que o desafiavam, como era o caso das que integravam a disciplina de matemática e dos questionamentos que a professora fazia à classe.

A tendência a gostar do ambiente escolar foi uma característica constatada através de entrevista. Nessa perspectiva, os pais afirmaram seguramente o gosto do filho pela escola, professoras e colegas.

Demonstrou a capacidade de estabelecer relaçóes entre causa e efeito, explicando que cola gliter não sai do papel porque é um tipo de cola, e deduzindo o que faz com que o macaco-prego seja assim denominado.

Vinny ouviu a professora dizendo a um aluno que havia errado que a cola gliter não sairia mais e veio me explicar:

- Cola gliter não sai mais porque é cola e gruda no papel. (Registros do diário de campo).

O Pensamento crítico foi evidenciado ao criticar atitudes e corrigir colegas e professores, argumentar, avaliar e questionar informaçóes e jogos.

A professora anunciou que iriam mudar de assunto e trabalhar com os animais. Vinny começou a dizer que animais eram chatos. A professora perguntou por que ele estava falando aquilo, se ele gostava de animais.

- E você gosta da natureza - disse uma colega.

- Mas a natureza é de verdade, não é um desenho - respondeu Vinny. (Registros do diário de campo).

Quanto à característica distração, tédio e desmotivação quando a tarefa não lhe é interessante, Vinny mostrou-se desinteressado em aprender a amarrar seus cadarços, quando a 
professora tentou lhe ensinar; recusou-se a copiar o cabeçalho da lousa, ao usar o caderno; brincava, ao invés de fazer determinadas atividades, as quais envolviam desenho e pintura ou eram muito simples para ele, como completar palavras com a sílaba que faltava; saía de seu lugar para desenhar na lousa ou conversava e brincava, enquanto seus colegas expunham os resultados de seus trabalhos.

Havia uma sequência de ilustraçóes coladas no caderno e Vinny mudou de atividade, indo pintar o índio do texto informativo, sem ter terminado a pintura anterior. Continuou com brincadeiras. (Registros do diário de campo).

Conforme Panzeri (2006), é comum a indisposição de alunos com AH/SD para trabalhar com assuntos que fogem aos seus interesses e, por conta disso, é preciso que o educador os ajude a encontrar conexóes com aquilo que lhes agrada para que seus horizontes exploratórios se ampliem.

Com relação a essas características de aprendizagem, também estiveram presentes nos alunos precoces participantes da pesquisa de Becker (1997): boa memória, gosto pelos colegas e professora, atenção e concentração.

Vinny demonstrou possuir um amplo vocabulário em três situações, o qual lhe permitia responder perguntas que outras crianças destinavam à professora, bem como empregar corretamente palavras pouco usuais, como é o caso de emaranhado. A presença de amplo vocabulário é equivalente ao que Becker (1997) identifica e denomina, nos participantes de sua pesquisa, como linguagem avançada.

Aparentemente, procurou ser superior, quando alterou o nome do animal que criara, aumentando-o, depois de ver que seu amigo havia criado um nome maior que o seu. Em outra ocasião, além de superar seus colegas no volume de informaçóes pesquisadas, levou objetos relacionados ao tema para classe.

Sua capacidade de fazer relatos ricos em detalhes esteve presente quando encenou uma história de sua autoria e ao falar a respeito de um texto lido à classe há dias, recordando-se de diversos detalhes deixados de lado pelos colegas.

Vinny explorava temas em profundidade, quando estes eram de seu interesse, como aconteceu com a pesquisa sobre dinossauros, na qual surpreendeu a todos pela quantidade de dados que trouxe, além dos objetos destinados a complementar a aula (livro sobre o assunto e dinossauro de brinquedo).

Estabelecer relaçôes entre informaçóes adquiridas anteriormente e novos conhecimentos foi uma característica percebida em três situaçóes; uma delas foi quando relacionou o conteúdo da aula com um desenho que assistiu na televisão. Outra, ao descobrir que capuz e touca são sinônimos e, por fim, percebendo que o conteúdo da pesquisa realizada por determinado colega era semelhante ao exposto anteriormente, por outra aluna.

Vinny pergunta:

- O que é capuz?

A professora mostra na capa em que ele está usando o que é denominado de capuz e ele diz:

- Ah, é que a gente chama isto de touca. (Registros do diário de campo). 
Sua capacidade em fazer generalizaçôes foi expressa uma única vez. Nessa ocasião, generalizou o meio pelo qual o animal é gerado, conforme sua proximidade com outro.

Vinny pergunta:

- Prô, o cachorro mama?

- Sim.

- E a galinha?

- Não.

- Então o galo não - disse ele. (Registros do diário de campo).

O encontro de satisfação ao pensar e discutir sobre o que leu esteve presente quando se propiciava aos alunos a oportunidade de falar sobre textos lidos. Diante dessa oportunidade, Vinny se motivava e se envolvia intensamente.

Concluída a atividade, a professora perguntou:

- Quem lembra a história "Eugênio, o gênio"?

- Eu lembro! - disse ele.

Logo em seguida, reclamou porque não havia recebido uma folha para desenhar, mas acabou se envolvendo com os questionamentos feitos a respeito do texto e não tocou mais no assunto. (Registros do diário de campo).

Vinny revelou rapidez na identificação de inconsistências em cinco situações, nas quais questionava a professora acreditando ter ouvido incoerências em sua fala ou discordava da escolha dos colegas, como ocorreu quando as cores eleitas para as figuras geométricas resultaram em um desenho com rua verde e copa de árvore vermelha.

- Depois da prova teremos aula de Arte e depois vamos ensaiar a música para o dia das máes disse a professora.

Vinny se levantou e disse:

- Mas você não falou que a gente ia na aula de informática?

- Ah é, tem razão, hoje é quinta, tem aula de informática. (Registros do diário de campo).

$\mathrm{O}$ aluno era rápido em estabelecer relaçóes e compreender significados, tanto que, em determinada ocasião, seus colegas não entendiam o que a professora estava solicitando e só passaram a compreender depois que Vinny deu exemplos corretos. Ele pintou um coelho conforme as características do animal que eram expressas em uma música cantada anteriormente à pintura, o que ocasionou estranhamento em uma de suas colegas, ao perceber que ele havia colorido apenas os olhos e utilizando ainda, a cor vermelha. Quando a professora perguntou quais eram os alunos que gostariam de expor o que haviam compreendido sobre uma leitura, Vinny e outros três foram os únicos a manifestarem esse desejo.

Com relação à atitude de questionamento e busca de informaçóes, já vimos que Vinny era um aluno curioso e estava sempre perguntando sobre o que desconhecia; acrescenta-se a isso o modo com que se comprometia com a busca de informaçôes, durante atividades de pesquisa.

A fim de localizar características específicas de alunos com indicadores de AH/SD produtivo-criativo, Pérez (2004) investigou seis alunos com características do tipo criativo- produtivo e três com características do tipo acadêmico, todos matriculados na $8^{a}$ série ( $9^{\circ}$ ano) do Ensino Fundamental. Em decorrência dos propósitos de nosso estudo, vamos nos deter aos participantes do segundo grupo: 
Ao examinar as características de aprendizagem de três alunos com indicadores de AH/SD do tipo acadêmico, a autora constatou que todos tinham notas altas na escola, e que seus professores consideravam que possuíam vocabulário, memória, capacidade de aprendizagem e de observação muito bons. Dois desses alunos faziam perguntas provocativas com frequência e todos tinham facilidade em fazer generalizaçóes, segundo os professores. Porém, os alunos autoavaliaram tais características de forma menos positiva, o que, de acordo com a autora, está associado ao perfeccionismo e excesso de exigência para consigo.

O participante de nosso estudo também tinha boas notas na escola, contudo, é relevante enfatizar que existem alunos com AH/SD que apresentam baixo rendimento (RENZULLI, 2004; ASPESI, 2007), o qual pode resultar de causas individuais: depressão, ansiedade, perfeccionismo e baixa autoestima; ou de causas ambientais: aulas monótonas e falta de estímulos ou o desejo de se igualar aos outros alunos para não ser excluído do grupo.

\section{Consideraçóes finais}

Vinny é um aluno que se destaca perante seu grupo etário e que, por vezes, chega a tumultuar o andamento das aulas com questionamentos incessantes, críticas e brincadeiras. Há momentos em que apresenta comportamentos inapropriados que derivam da desmotivação ocasionada pela facilidade das atividades oferecidas, outras vezes, por querer atrair a atenção dos demais. É comum que crianças como Vinny, tidas como "inteligentes", sejam vistas como alunos autossuficientes, que não necessitam de qualquer forma de atenção individualizada, o que é um equívoco, pois, não encontrando desafios em sua escolarização, o aluno precoce pode perder o interesse pela escola e procurar alternativas para se distrair, ao invés de se envolver com as tarefas estudantis. De acordo com Panzeri (2006), a prática de atitudes que incomodam a classe e perturbam os colegas é frequentemente desencadeada pela percepção de falta de atenção e satisfação de suas necessidades. Para evitar tal situação, é preciso enriquecer as experiências escolares do aluno, para que ultrapasse os conhecimentos que já dispóe e produza novos saberes.

As características de pensamento criativo têm abundante importância, em função de ser a criatividade um dos anéis que determinam a presença de superdotação. Similarmente, encontram-se as características de aprendizagem, as quais se relacionam à habilidade acima da média. Contudo, Renzulli e Reis (1985) esclarecem que os três anéis são desproporcionais, de sorte que náo é necessário que tenham as mesmas dimensóes, pois ocorre uma compensação entre os componentes maiores e os menores. Ademais, afirmam que a criatividade e o comprometimento com a tarefa são passíveis de se desenvolver por meio de ensino e estímulos adequados, embora nem todas as pessoas respondam satisfatoriamente à estimulação.

Em decorrência das influências do ambiente no desenvolvimento das habilidades superiores, salienta-se a importância e a necessidade de que os profissionais da educação ampliem seus conhecimentos acerca desses alunos a fim de que possam reconhecê-los e proporcionar-lhes as condiçóes propícias para o estímulo de suas potencialidades.

Cumpre evidenciar que o aluno observado pode apresentar outras características, além das que foram observadas, mas que não se manifestaram durante os momentos em que estávamos em sala de aula, realizando a coleta de dados. Nessa perspectiva, ressalta-se que as situaçóes de sala de aula (o contexto) tanto podem incentivar quanto impedir a expressão de 
certas características, as quais são igualmente influenciadas pela personalidade do indivíduo, assim como pela própria questão de gênero. Freeman e Guenther (2000) apontam estudos que revelam uma desvantagem por parte das meninas com relação à disciplina de matemática, uma vez que ingressam nas instituiçóes formais de ensino com menos experiências nesse campo, quando comparadas aos meninos. Isso ocorre porque pais de crianças do sexo feminino tendem a oferecer menor quantidade de brinquedos e jogos que envolvem matemática que os pais de crianças do sexo masculino. Para Pérez e Freitas (2012), o fato de as mulheres serem percebidas como menos criativas também está associado aos estímulos que o ambiente oferece diferenciadamente aos gêneros, para o desenvolvimento de componentes necessários à produção criativa.

Todos esses fatores devem ser levados em consideração para que haja a possibilidade de identificar corretamente, os alunos precoces, os quais podem ter na precocidade um indicador de superdotação que se confirmará futuramente, desde que oferecidas as condiçóes apropriadas. Não estamos querendo dizer que a superdotação é um fenômeno determinado pelo ambiente, mas que o desenvolvimento satisfatório das potencialidades, tal como a motivação para se dedicar à área de domínio e atingir altos níveis de produtividade estão intimamente relacionados a condicionantes externos. Porém, ressalta-se que os estímulos e incentivos requeridos pelo pleno desenvolvimento dos potenciais e das habilidades não devem estar desacompanhados dos cuidados que garantam à criança desfrutar o período da infância, dispondo de tempo para brincar e podendo se comportar como qualquer outra de mesma idade, pois, às vezes há incompreensão quanto a contradição entre comportamentos ora avançados e ora adequados à faixa etária. É preciso ter claro que a criança precoce é, antes de tudo, uma criança.

\section{REFERÊNCIAS}

ALENCAR, E.M.L.S. Criatividade e educação de superdotados. Petrópolis: Vozes, 2001.

ALENCAR, E.M.L.S.; FLEITH, D.S. Superdotados: determinantes, educação e ajustamento. 2.ed. São Paulo: EPU, 2001.

ASPESI, C.C. A família do aluno com altas habilidades/superdotação. In: FLEITH, D.S. (Org.). A construção de práticas educacionais para alunos com altas habilidades/superdotação: o aluno e a família. Brasília, DF: MEC, SEESP, 2007. p.29-47.

BECKER, M.A.A. Educação especial: estímulo ambiental e potencial para altas habilidades em préescolares. 1997. 199f. Dissertação (Mestrado em Psicologia) - Programa de Pós-Graduação, Instituto de Psicologia, Pontifícia Universidade Católica do Rio Grande do Sul, Porto Alegre, 1997.

BENITO, Y. Definición, pautas de identificación y educación para padres y profesores. In: BENITO, Y. (Org.). Intervención e investigación psicoeducativas en alumnos superdotados. 2.ed. Salamanca: Amarú Ediciones, 2000. p.79-93.

BRASIL. Projeto escola viva: garantindo o acesso e permanência de todos os alunos na escola - alunos com necessidades educacionais especiais. Brasília, DF: MEC, SEESP, 2002.

CÂMARA, C.G. Alto-alfabetização precoce: indício de superdotação ou resposta a um ambiente rico em estímulos? 1999. 159f. Dissertação (Mestrado em Psicologia) - Programa de Pós-Graduação, Instituto de Psicologia, Universidade de São Paulo, São Paulo, 1999.

CUPERTINO, C.M.B. Um olhar para as altas habilidades: construindo caminhos. São Paulo: FDE, 2008. 
FORNO, L.F.D. Precocidade na educação infantil: e agora professoras? 2011. 118f. Dissertação (Mestrado em Educação) - Programa de Pós-Graduação, Centro de Educação, Universidade Federal de Santa Maria, Santa Maria, 2011.

FORTES, C.C.; FREITAS, S.N. PIT - Programa de incentivo ao talento: um relato das experiências pedagógicas realizadas com alunos com características de altas habilidades. Revista Educação Especial, Santa Maria, v.20, n.29, p.1-6, 2007.

FREEMAN, J.; GUENTHER, Z.C. Educando os mais capazes: idéias e açóes comprovadas. São Paulo: EPU, 2000.

FREITAS, S.N. Altas habilidades/ superdotação em pesquisa: um olhar dirigido. In: OMOTE, S.; OLIVEIRA, A.A.S.; CHACON, M.C.M. (Org.). Ciência e conhecimento em educação especial. São Carlos: Marquezine \& Manzini; Marília: ABPEE, 2014. p.125-134.

MALDANER, E.B. O desenho da figura humana e a identificação precoce de superdotação. 1996. 1466. Dissertação (Mestrado em Psicologia Social e da Personalidade) - Programa de Pós-Graduação, Instituto de Psicologia, Pontifícia Universidade Católica do Rio Grande do Sul, Porto Alegre, 1996.

MANZANO, E.S. La superdotación intelectual. Málaga: Ediciones Aljibe, 2009.

MARQUES, D.M.C. Reconhecimento por meio de indicadores da precocidade do aluno na educação infantil. 2013. 159f. Dissertação (Mestrado em Educação Especial) - Programa de Pós-Graduação, Centro de Educação e Ciências Humanas, Universidade Federal de São Carlos, São Carlos, 2013.

NAKANO, T.C.; WECHSLER, S.M. Identificação e avaliação do talento criativo. In: FLEITH, D.S. (Org.). Desenvolvimento de talentos e altas habilidades: orientação a pais e professores. Porto Alegre: Artmed, 2007. p.87-98.

PANZERI, M.V. Los niños talentosos y superdotados una respuesta educativa: "enriquecimiento en la escuela común”. In: FREITAS, S.N. (Org.). Educação e altas habilidades/superdotação: a ousadia de rever conceitos e práticas. Santa Maria: Ed. da UFSM, 2006. p.257-277.

PÉREZ, S.G.P.B. Gasparzinho vai à escola: um estudo sobre as características do aluno com altas habilidades produtivo-criativo. 2004. 306f. Dissertação (Mestrado em Educação) - Programa de Pós-Graduação, Faculdade de Educação, Pontifícia Universidade Católica do Rio Grande do Sul, Porto Alegre, 2004. PÉREZ, S.G.P.B.; FREITAS, S.N. A mulher com altas habilidades/superdotação: à procura de identidade. Revista Brasileira de Educação Especial, Marília, v.18, n.4, p.677-694, 2012.

RENZULLI, J.S. Desarrollo del talento en las escuelas. Programa práctico para el total rendimiento escolar mediante el modelo de enriquecimiento escolar. In: BENITO, Y. (Org.). Intervención e investigación psicoeducativas en alumnos superdotados. Salamanca: Amarú Ediciones, 2000. p.175-217.

RENZULLI, J.S. O que é esta coisa chamada superdotação e como a desenvolvemos? Uma retrospectiva de vinte e cinco anos. Educação, Porto Alegre, v.52, n.1, p.75-131, 2004.

RENZULLI, J.S.; REIS, S.M. The schoolwide enrichment model: a comprehensive plan for educational excellence. Connecticut: Creative Learning Press, 1985.

RICHARDSON, R.J. Pesquisa social: métodos e técnicas. 3.ed. São Paulo: Atlas S.A., 1999.

TURETA, C.; ALCADIPANI, R. Entre o observador e o integrante da escola de samba: os não-humanos e as transformaçóes durante uma pesquisa de campo. $R A C$, Curitiba, v.15, n.2, p.209-227, 2011.

Recebido em: 07/03/2015

Reformulado em: 13/11/2015

Aprovado em: 18/11/2015 